\title{
SipA, SopA, SopB, SopD and SopE2 effector proteins of Salmonella enterica serovar Typhimurium are synthesized at late stages of infection in mice
}

Correspondence

M. N. Giacomodonato

monicagiaco@yahoo.com.ar

Received 23 September 2006

Revised 7 December 2006

Accepted 8 December 2006

\author{
M. N. Giacomodonato, ${ }^{1}$ S. Uzzau, ${ }^{2}$ D. Bacciu, ${ }^{2}$ R. Caccuri, ${ }^{1}$ S. H. Sarnacki, ${ }^{1}$ \\ S. Rubino ${ }^{2}$ and M. C. Cerquetti ${ }^{1}$ \\ ${ }^{1}$ Centro de Estudios Farmacológicos y Botánicos CEFyBO-CONICET, Universidad de Buenos \\ Aires, Facultad de Medicina, Departamento de Microbiología, Parasitología e Immunología, \\ Buenos Aires, Argentina \\ ${ }^{2}$ Dipartimento di Scienze Biomediche, Università di Sassari, Italy
}

\section{INTRODUCTION}

Salmonella enterica has evolved refined mechanisms to invade, and survive and replicate within, host cells. The outcome of these interactions is determined by both the host species and the Salmonella serotype. For instance, S. enterica serovar Typhi causes a systemic disease in humans known as typhoid fever, whereas patients infected with $S$. enterica serovar Typhimurium (serovar Typhimurium) develop a localized gastroenteritis and lymphadenitis resulting in diarrhoea. Similar to humans, in calves, infection with serovar Typhimurium remains localized to the intestine. In contrast, serovar Typhimurium infection in mice results in a systemic typhoid-fever-like disease (Santos \& Bäumler, 2004; Zhang et al., 2003).

Two major virulence determinants involved in Salmonella pathogenesis are encoded in large chromosomal pathogenicity islands called Salmonella pathogenicity island (SPI)-1

Abbreviations: i.g., intragastric(ally); iNOS, inducible nitric oxide synthase; i.p., intraperitoneal(ly); MLN, mesenteric lymph node; serovar Typhimurium, Salmonella enterica serovar Typhimurium; SPI, Salmonella pathogenicity island; TTSS, type III secretion system. and SPI-2 (Galan, 2001). Both SPI-1 and SPI-2 encode separate type III secretion systems (TTSSs) that introduce virulence proteins into the host environment, either by translocation directly into host cells or, possibly, by secretion into the vicinity of host cells (Galan, 2001; Waterman \& Holden, 2003). Upon ingestion, Salmonella serotypes exhibit, in mammals, a tropism for intestinal lymphoid tissue (Reis et al., 2003; Santos \& Baümler, 2004; Tsolis et al., 1999). In mice, serovar Typhimurium preferentially invades the $\mathrm{M}$ cells of the follicle-associated epithelium of Peyer's patches (Clark et al., 1994; Jones et al., 1994). Invasion of epithelial cells is governed by the Salmonella SPI-1-encoded TTSS-1 (Galan, 2001). Serovar Typhimurium senses environmental factors such as oxygen concentration, osmolarity and $\mathrm{pH}$, which act as regulators for expression of TTSS-1 (Bajaj et al., 1996). Alternatively, serovar Typhimurium can rapidly enter the bloodstream from the intestinal lumen by a TTSS-1-independent route. This pathway involves bacterial transport by CD-18expressing phagocytes (macrophages and/or dendritic cells) to systemic sites of infection (Vazquez-Torres et al., 1999). It is generally accepted that SPI-1 and SPI-2 TTSSs play a dichotomous role during the intestinal and systemic 
phases of salmonellosis. Whereas TTSS-1 plays an essential function in colonization of the bovine intestine and in bovine enteropathogenesis (Zhang et al., 2003), this virulence trait has been reported to have little or no role in systemic infection (Galan, 2001). Conversely, the SPI-2encoded TTSS (TTSS-2) is more strongly related to systemic virulence and its associated pathology than to intestinal disease (Galan, 2001). It is also well documented that SPI-1 is essential for invasion of non-phagocytic cells, whereas SPI-2 is required for intracellular survival and proliferation in phagocytes (Marcus et al., 2000).

In contrast to the current model of SPI-mediated pathogenesis, it has been shown that some SPI-1 effectors are induced upon invasion of both phagocytic and nonphagocytic cells, suggesting that they may also be required post-invasion (Pfeifer et al., 1999). In this regard, elegant studies performed by Steele-Mortimer et al. (2002) have demonstrated that SPI-1 is essential for intracellular replication. On the other hand, Brown et al. (2005) have recently demonstrated that SPI-2 expression precedes penetration of the intestinal epithelium. Therefore, it is important to carefully consider the dichotomous roles of SPI-1 and SPI2 in the intestinal and/or systemic paradigm of serovar Typhimurium infection (Coburn et al., 2005; Schlumberger \& Hardt, 2006). To analyse whether SPI-1 effector proteins participate in the late stages of murine salmonellosis, we investigated the presence of SipA, SopA, SopB, SopD and SopE2 during Salmonella infection of mice.

\section{METHODS}

Bacterial strains. This work was carried out using strains of serovar Typhimurium derived from strain ATCC 14028 and tagged with the 8 aa FLAG epitope tag peptide. Strains SSM 3213 (sopA::3 $\times$ FLAG sopE2::3 $\times$ FLAG cat $::$ FLAG $),$ SSM $3214(s o p D:: 3 \times$ FLAG

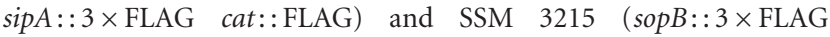
avrA::3 $\times$ FLAG cat::FLAG) of serovar Typhimurium were obtained using the method described by Uzzau et al. (2001). $3 \times$ FLAG epitope tails were added to the ends of the $\operatorname{sip} A, \operatorname{sop} A$, $s o p B, \operatorname{sopD}$ and $s o p E 2$ genes. The $3 \times$ FLAG epitope is a sequence of three tandem FLAG epitopes (22 aa). For each tagged mutant, a pair of primers was designed to amplify a $3 \times$ FLAG- $^{-}$and kanR-coding sequence by using plasmid pSUB11 (Uzzau et al., 2001). The 3' ends of these oligonucleotides were complementary to the first $20 \mathrm{nt}$ of the pSUB11 $3 \times$ FLAG coding region (GACTACAAAGACCATGACGG, forward primers) and to the $20 \mathrm{nt}$ of the pSUB11 priming site 2 (CATATGAATATCCTCCTTAG, reverse primers). The $5^{\prime}$ ends of the oligonucleotides were designed to be homologous to the last $40 \mathrm{nt}$ of each tagged gene, not including the stop codon (forward primers), and to the $40 \mathrm{nt}$ immediately downstream of the gene stop codon (reverse primers).

Preparation of secreted proteins. Bacterial strains were grown under conditions to induce SPI-1 gene expression, as described by Miki et al. (2004). Bacterial culture supernatants and pellets were obtained to investigate secreted proteins and cell-associated proteins, respectively (Pucciarelli et al., 2002). Bacteria were grown in LB broth containing $0.3 \mathrm{M} \mathrm{NaCl}$ overnight at $37^{\circ} \mathrm{C}$ without aeration (SPI-1-inducing conditions). For the isolation of proteins released into the culture supernatants (secreted proteins), cells were pelleted by centrifugation and $2 \mathrm{ml}$ supernatant was collected from each sample. The supernatants were then filtered $(0.45 \mu \mathrm{m}$ pore size $)$, and the proteins were precipitated with $25 \%$ TCA and sedimented by high-speed centrifugation (14000 $\mathrm{g}$ for $30 \mathrm{~min}$ ). The pellet was washed in cold acetone and resuspended in PBS and Laemmli buffer. Four independent extractions for each sample were added together to minimize differences in protein recovery from sample to sample. The proteins were then boiled for 5-10 $\mathrm{min}$, and an aliquot of each sample was separated by SDS-PAGE (10\% gel) (Raffatellu et al., 2005). Finally, effector proteins were immunodetected using mouse anti-FLAG M2-peroxidase (HRP) mAbs (Sigma).

Animals. Six- to eight-week-old BALB/c mice were purchased from the Facultad de Ciencias Exactas y Naturales, Universidad de Buenos Aires, and kept in our animal house throughout the experiments. All experiments were performed in accordance with the guidelines of the School of Medicine Animal Care and Use Committee.

Virulence assays. Serial dilutions of bacterial suspensions were used to inoculate groups of six mice intragastrically (i.g.) $(500 \mu \mathrm{l})$ or intraperitoneally (i.p.) $(100 \mu \mathrm{l})$. Survival of infected mice was recorded for a minimum of 4 weeks. $\mathrm{LD}_{50}$ was calculated by the method of Reed \& Muench (1938).

Organ colonization. Groups of 10 mice were inoculated i.p. with $10^{2}$ or $10^{7}$ c.f.u. per animal of the SSM strains and were euthanized at 5 days or $12-18 \mathrm{~h}$ after inoculation, respectively. Another group of 10 mice were inoculated i.g. with $10^{6}$ or $10^{8}$ c.f.u. per animal of the SSM strains and were euthanized at 8 or 5 days after inoculation, respectively. Spleens and mesenteric lymph nodes (MLNs) were removed and homogenized in $1 \mathrm{ml}$ sterile saline. Appropriate dilutions were plated on tripticase soy agar (TSA) for determination of colony counts.

Murine salmonellosis. Groups of 10 mice were inoculated i.p. with two different lethal doses $\left(10^{2}\right.$ and $10^{7}$ c.f.u. per mouse) of tagged serovar Typhimurium strains. A different group of animals were inoculated i.g. with $10^{6}$ c.f.u. per mouse of tagged serovar Typhimurium strains. To prepare the inocula, bacteria were grown overnight in $\mathrm{LB}$ at $37^{\circ} \mathrm{C}$. Cultures were diluted in physiological saline for i.p. and i.g. inoculation. Viable bacteria in inocula were quantified by dilution and plating onto LB agar plates containing appropriate antibiotics.

Preparation of bacterial extracts from spleens and MLNs. Bacterial extracts from spleens and MLNs of mice were prepared as described by Dominguez-Bernal et al. (2004), with modifications. Mice were euthanized when moribund. Animals infected i.p. with $10^{7}$ c.f.u. per mouse were euthanized at $12-18 \mathrm{~h}$ post-infection. Mice receiving $10^{2}$ c.f.u. i.p. were euthanized at day 5 post-inoculation. On the other hand, mice inoculated i.g. with $10^{6}$ c.f.u. were euthanized at day 8 post-infection. Spleens and MLNs were aseptically recovered and homogenized in $1.5 \mathrm{ml}$ cold double-distilled water. To determine bacterial counts, $100 \mu \mathrm{l}$ of this homogenate was serially diluted in PBS and plated on TSA. The rest of the homogenate was centrifuged $\left(9000 \mathrm{~g}, 10 \mathrm{~min}, 4{ }^{\circ} \mathrm{C}\right)$ and resuspended in $500 \mu \mathrm{l}$ freshly prepared lysis buffer $\left(120 \mathrm{mM} \mathrm{NaCl}, 4 \mathrm{mM} \mathrm{MgCl}_{2}\right.$, $20 \mathrm{mM}$ Tris/ $\mathrm{HCl}, \mathrm{pH} 7.5,1 \%$ Triton-X100) supplemented with protease inhibitors (complete EDTA-free cocktail, Roche). After $1 \mathrm{~h}$ incubation at $4{ }^{\circ} \mathrm{C}$, samples were clarified by centrifugation at $1000 \mathrm{~g}$ for $2 \mathrm{~min}$ at $4^{\circ} \mathrm{C}$. Supernatants were further centrifuged $\left(18000 \mathrm{~g}, 10 \mathrm{~min}, 4^{\circ} \mathrm{C}\right.$ ) and the bacteria-containing pellets were washed once with cold PBS and resuspended in an appropriate volume of PBS and Laemmli buffer. Protein extracts were then boiled for 5-10 $\mathrm{min}$, and an aliquot of each sample was resolved by $10 \%$ SDS-PAGE for detection of $3 \times$ FLAG-tagged proteins by Western blotting.

Immunodetection analysis. FLAG and $3 \times$ FLAG fusion proteins were immunodetected using mouse anti-FLAG M2-peroxidase 
(HRP) mAbs (Sigma). Detection was performed by chemiluminescence (Luminol, Santa Cruz Biotechnology). Blots were scanned, and the intensity of the signals was determined using the public domain NIH Image program (http://rsb.info.nih.gov/nih-image/).

\section{RESULTS}

\section{Epitope tagging does not affect the invasive ability of serovar Typhimurium}

In order to assess whether tagging of SPI-1 genes modifies the wild-type phenotype of serovar Typhimurium strains in vivo, we inoculated mice i.p. and i.g., as described above. The survival rate and the colonization of MLNs and spleens were determined at different time points. The results are summarized in Table 1. No differences were observed between the $\mathrm{LD}_{50}$ of the wild-type serovar Typhimurium (ATCC 14028) and any of the tagged Salmonella strains, regardless of the route of inoculation. Similarly, colonization of internal organs was not significantly different in any of the experimental groups studied. These results demonstrate that the tagging technique does not impair the invasiveness of the strains.

\section{SipA, SopA, SopB, SopD and SopE2 are synthesized and secreted in vitro by tagged mutants of serovar Typhimurium}

To investigate the capacity of tagged mutants to synthesize and secrete SPI-1 effector proteins, bacterial strains were grown under SPI-1 culture conditions (as described in Methods). SipA, SopA, SopB, SopD and SopE2 were synthesized and secreted by bacteria grown under SPI-1 conditions
(Fig. 1). These results indicate that the SPI-1 secretion system is conserved and functioning in the tagged strains. We were unable to detect AvrA protein under any of the growth conditions tested. The whole avrA gene plus $300 \mathrm{nt}$ downstream were sequenced in strain SSM 3215, confirming the correct fusion of the ORF with the $3 \times$ FLAG coding sequence. It is worth pointing out here that the avrA gene is present in approximately $80 \%$ of S. enterica serovars, although few of them synthesize the effector (Streckel et al., 2004).

\section{SipA, SopA, SopB, SopD and SopE2 are synthesized during murine salmonellosis}

We investigated the synthesis of these SPI-1 effectors (associated with the initial stages of Salmonella infection) during acute lethal infection. Mice were inoculated i.p., a route of infection that does not require invasion of the intestinal epithelium (Galan \& Curtiss, 1989), with high doses of tagged strains. In this way, we ensured that sufficient infecting bacteria could be recovered from the MLNs and spleen. We found that serovar Typhimurium recovered from internal organs 12-18 h after infection synthesized all the effector proteins studied (Fig. 2a). SopA was the effector detected in the lowest amount. Similar levels of the effector proteins, quantified as band intensity, were detected in bacteria recovered from MLNs and spleens at this early time point (Fig. 2c, black bars).

To rule out residual expression of the effector proteins from in vitro bacterial growth, we investigated longer periods after infection. For this purpose, animals were inoculated i.p. with low doses of bacteria $\left(10^{2}\right.$ c.f.u. per mouse). In this

Table 1. Virulence of the different serovar Typhimurium strains used in this study

BALB/c mice were inoculated i.p. or i.g. with wild-type (ATCC 14028) and tagged (SSM 3213, SSM 3214 and SSM 3215) strains of serovar Typhimurium at the doses indicated in Methods. ND, Not determined.

\begin{tabular}{|c|c|c|c|c|c|c|}
\hline \multirow[t]{2}{*}{ Strain } & \multicolumn{2}{|c|}{$\mathrm{LD}_{50}{ }^{*}$} & \multicolumn{2}{|c|}{ Colonization (i.p.) } & \multicolumn{2}{|c|}{ Colonization (i.g.) } \\
\hline & i.p. & i.g. & log c.f.u. per spleen & $\log$ c.f.u. per MLN & log c.f.u. per spleen & $\log$ c.f.u. per MLN \\
\hline ATCC 14028 & $<10$ & $6 \times 10^{4}$ & $8.10 \pm 0.31 \dagger$ & $7.50 \pm 0.22 \dagger$ & $6.27 \pm 0.51 \ddagger$ & ND \\
\hline \multirow[t]{2}{*}{ SSM 3213} & $<10$ & $2.5 \times 10^{4}$ & $8.35 \pm 0.37 \dagger$ & $7.87 \pm 0.81 \dagger$ & $5.59 \pm 0.46 \ddagger$ & ND \\
\hline & & & $8.08 \pm 0.12 \S$ & $6.77 \pm 0.50 \S$ & $7.51 \pm 0.70 \|$ & $6.69 \pm 0.54 \|$ \\
\hline \multirow[t]{2}{*}{ SSM 3214} & $<10$ & $2 \times 10^{4}$ & $7.91 \pm 0.12 \dagger$ & $7.23 \pm 0.21 \dagger$ & $6.41 \pm 0.68 \ddagger$ & ND \\
\hline & & & $7.10 \pm 0.80 \S$ & $6.85 \pm 0.71 \S$ & $7.07 \pm 0.50 \|$ & $6.70 \pm 0.41 \|$ \\
\hline \multirow[t]{2}{*}{ SSM 3215} & $<10$ & $3 \times 10^{4}$ & $8.27 \pm 0.30 \dagger$ & $7.58 \pm 0.36 \dagger$ & $5.93 \pm 0.32 \ddagger$ & ND \\
\hline & & & $7.54 \pm 0.30 \S$ & $6.74 \pm 0.51 \S$ & $7.14 \pm 0.34 \|$ & $6.72 \pm 0.26 \|$ \\
\hline
\end{tabular}

${ }^{*} \mathrm{LD}_{50}$ was calculated by the method of Reed \& Muench (1938). No differences were observed between the $\mathrm{LD}_{50}$ of the wild-type and those of any of the tagged serovar Typhimurium strains, regardless the route of inoculation.

$\dagger$ Organ colonization at $12-18 \mathrm{~h}$ after i.p. inoculation with $10^{7}$ c.f.u. per mouse.

$\ddagger$ Organ colonization at day 5 after i.g. inoculation with $10^{8}$ c.f.u. per mouse.

§Organ colonization at day 5 after i.p. inoculation with $10^{2}$ c.f.u. per mouse.

IIOrgan colonization at day 8 after i.g. inoculation with $10^{6}$ c.f.u. per mouse. Data are presented as mean \pm SEM for 10 mice. No differences were observed in the amount of colonizing bacteria recovered from animals inoculated with the wild-type or with any of the tagged strains of serovar Typhimurium, regardless of the route of inoculation. 
(a)
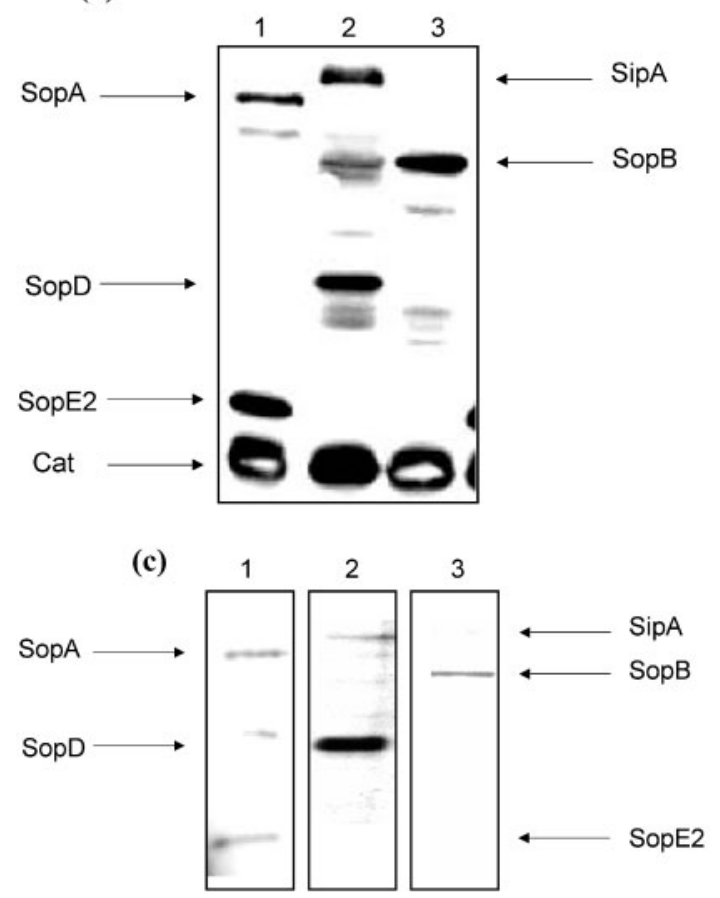

(b)

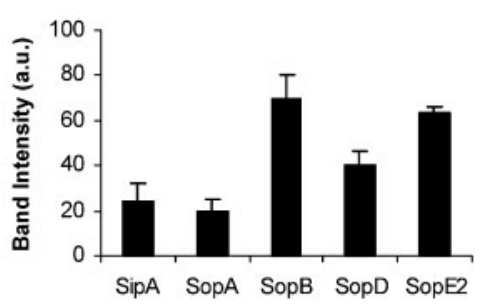

(d)

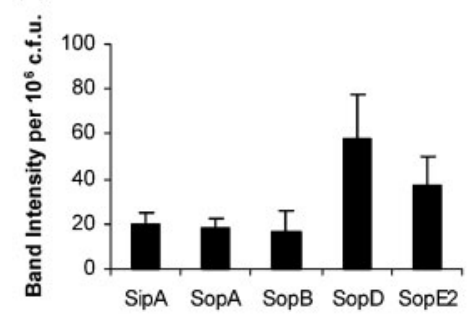

Fig. 1. Analysis of SipA, SopA, SopB, SopD and SopE2 (a) synthesis and (c) secretion in vitro under SPI-1 conditions. Bacterial pellets and bacterial supernatants were used to investigate cell-associated proteins and secreted proteins, respectively. Samples were subjected to SDS-PAGE and tagged proteins were detected by anti-FLAG antibodies. Each lane was loaded with material from approximately $10^{7}$ c.f.u. Lanes: 1, SSM 3213; 2, SSM 3214; 3, SSM 3215. (b) Densitometric analysis of effector levels present in the whole bacterial extract. Effector levels were normalized to Cat expression and presented in arbitrary units (a.u.). The Cat protein was used as an internal marker because it is very stable. A constitutively expressed epitope-tagged gene such as cat can be used as a positive control or internal reference (Uzzau et al., 2001). (d) Densitometric analysis of effector levels present in bacterial supernatants. Protein loading was normalized to $10^{6}$ c.f.u. Data are means $\pm S D$ from three independent experiments.

manner, we could recover infecting bacteria from MLNs and spleens several days after i.p. inoculation. We found that Salmonella strains isolated from mice after 5 days of infection continued to synthesize SipA, SopB, SopD and SopE2 (Fig. 2b). The amount of SipA, SopB and SopD detected at day 5 was significantly lower than that observed in bacteria recovered $12-18 \mathrm{~h}$ post-i.p. inoculation (Fig. 2c, white bars). SopA, the effector protein detected in the lowest amount at $12-18 \mathrm{~h}$ (Fig. 2a), was not detected at day 5 (Fig. 2b, c). Conversely, SopE2 levels at day 5 after i.p. infection were significantly higher than those detected at earlier time points. This was observed in bacteria isolated from both MLNs and spleens (Fig. 2c).

We next investigated whether these SPI-1 effector proteins were synthesized during the late stages of Salmonella infection acquired by the natural route. For that purpose, animals were inoculated i.g. with $10^{6}$ c.f.u. per mouse of the tagged Salmonella strains. In these experiments, mice became moribund by day 8 post-inoculation. As shown in Fig. 3, serovar Typhimurium recovered from spleens and MLNs 8 days post-i.g. inoculation continued to synthesize SipA, SopB, SopD and SopE2. Once again, SopA was not detected.

\section{DISCUSSION}

Tagged strains of serovar Typhimurium were used to study in vitro synthesis and secretion of SPI-1 effector proteins SipA, SopA, SopB, SopD and SopE2. We also demonstrated in vivo that tagged strains are as virulent as the wild-type strain of serovar Typhimurium. Consequently, tagged strains were used to induce murine salmonellosis and to study effector protein synthesis at different stages of infection. Our data show that SPI-1 effectors, SipA, SopB, SopD and SopE2, are synthesized by the bacteria during the final phase of murine salmonellosis. Earlier work performed in vitro has demonstrated that some SPI-1 effectors, including SptP and SopB, persist within host cells for several hours after invasion, suggesting that there is continued secretion of these effectors post-invasion (Drecktrah et al., 2005; Kubori \& Galan, 2003).

In vitro studies can provide attractive models for in vivo gene regulation; however, caution must be exercised when attempting to extrapolate relevant in vivo signals from environmental cues that regulate virulence genes in vitro. There is little direct evidence to identify the conditions that 
(a)
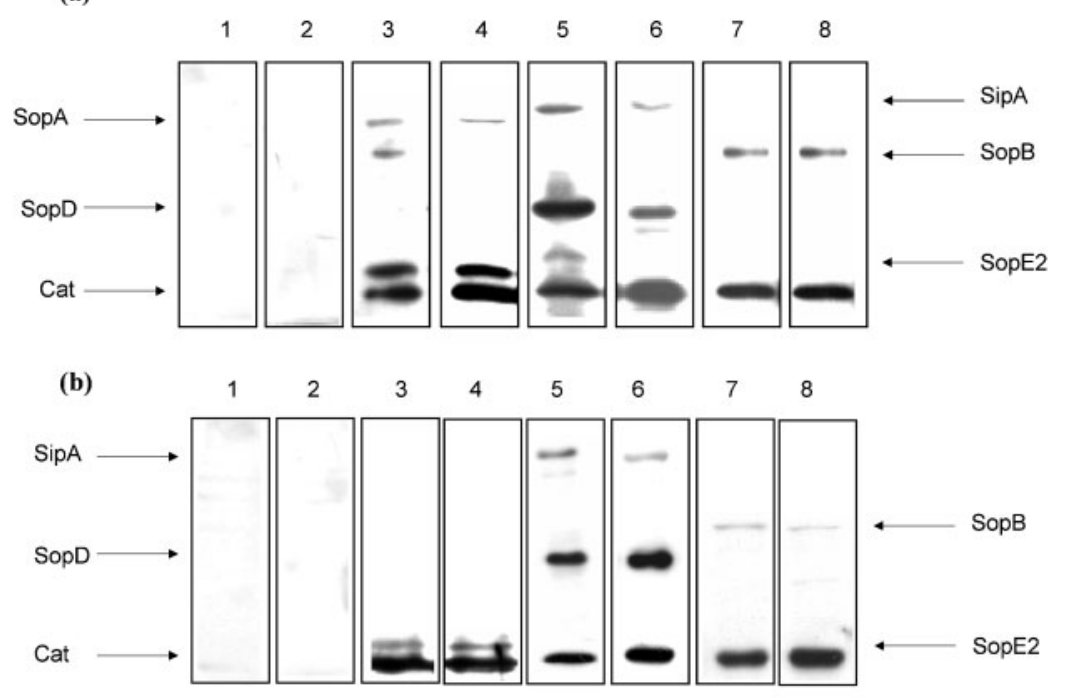

(c)

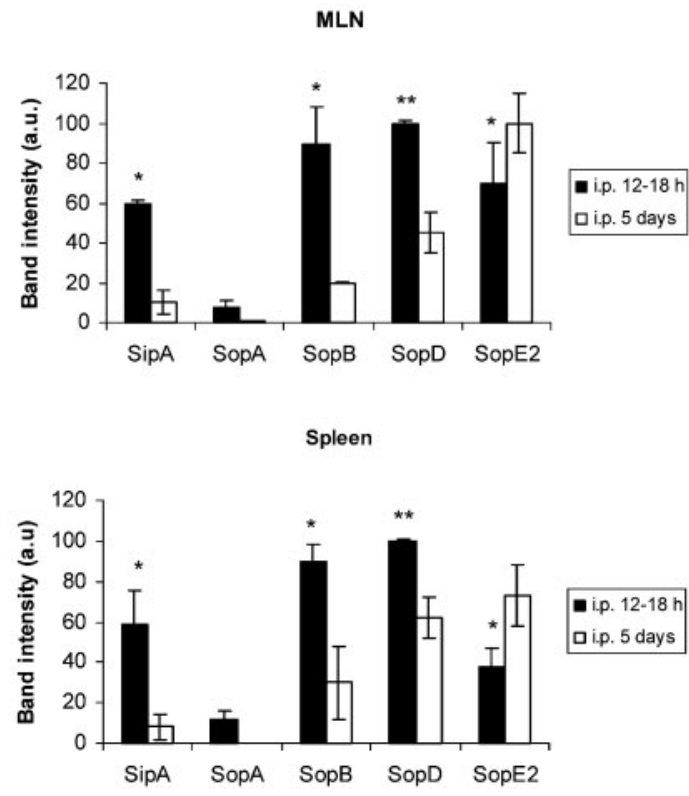

Fig. 2. Detection of $\operatorname{SipA}$, SopA, SopB, SopD and SopE2 in internalized bacteria recovered from spleens and MLNs after i.p. inoculation. Mice were inoculated i.p. with (a) $1 \times 10^{7}$ c.f.u. or (b) $1 \times 10^{2}$ c.f.u. of tagged strains of serovar Typhimurium. Internalized bacteria were recovered from spleens and MLNs at (a) 12-18 h postinoculation or (b) 5 days after inoculation. Proteins from internalized bacteria were extracted as described in Methods. Lanes: 1 and 2, MLN and spleen extracts, respectively, from control uninfected mice; 3 and 4, MLN and spleen extracts, respectively, from mice inoculated with SSM 3213; 5 and 6, MLN and spleen extracts, respectively, from mice inoculated with SSM 3214; 7 and 8, MLN and spleen extracts, respectively, from mice inoculated with SSM 3215. MLN protein extracts from two mice were pooled. Each lane was loaded with material from approximately $1 \times 10^{7}$ c.f.u. (c) Densitometric analysis of effector levels present in the whole bacterial extract. Effector levels were normalized to Cat expression and presented in arbitrary units (a.u.). Data are means $\pm S D$ from three independent experiments. ${ }^{*} P<$ $0.05 ;{ }^{\star \star} P<0.01$ (ANOVA). bacteria encounter at different sites during infection. Signals that regulate virulence genes in vitro may not be the same as those modulating these genes in vivo. In some cases, in vitro cues may operate by an artificial process that bypasses the in vivo signalling mechanism (Lucas \& Lee, 2000). To our knowledge, this is the first time that the synthesis of SPI-1 effector proteins has been documented in bacteria recovered from infected mice. SPI-1 effector proteins were detected several days after inoculation with low doses of the tagged strains, residual expression from the bacterial inoculum was therefore unlikely. Moreover, results from animals infected i.p. indicate that residual expression from the intestinal invasion stage could also be ruled out.

Most recently, Lawley et al. (2006) have shown by a microarray-based negative-selection screen that some SPI-1 genes contribute to long-term systemic infection in Nramp $1^{\mathrm{r}}$ mice. Therefore, there appears to be considerable functional overlap between SPI-1 and SPI-2 during pathogenesis. Most studies focus on the role played by SPI-1 effectors during the intestinal phase of salmonellosis, overlooking additional functions of SPI-1. The delayed synthesis of SipA, SopA, SopB, SopD and SopE2 demonstrated during murine infection suggests that SPI-1 effectors have potential actions in the post-invasion stages of the disease.

The effector protein genes $s o p B$, $s o p D$ and $s o p E 2$ are located in different regions of the Salmonella chromosome, and are present in a wide variety of Salmonella lineages, suggesting that these effector proteins may serve central virulence functions (Mirold et al., 2001). Although SopB, SopD and SopE2 are clearly involved in host cell invasion (Raffatellu 
(a)

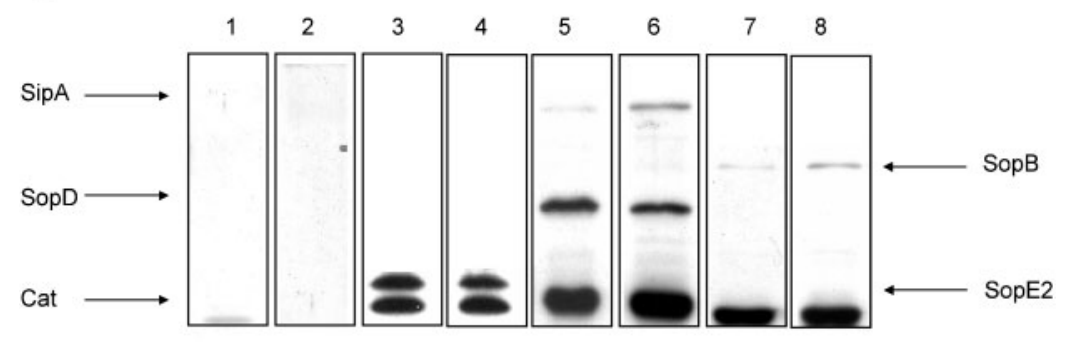

(b)

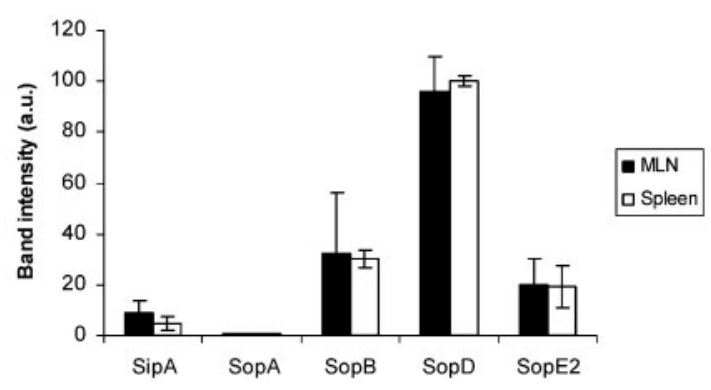

Fig. 3. (a) Detection of SipA, SopA, SopB, SopD and SopE2 in bacteria recovered from spleens and MLNs after infection through the natural route. Mice were inoculated i.g. with $1 \times 10^{6}$ c.f.u. and were euthanized 8 days after inoculation. Internalized bacteria were recovered from spleens and MLNs. Proteins from internalized bacteria were extracted as described in Methods. Lanes: 1 and 2, MLN and spleen extracts, respectively, from control uninfected mice; 3 and 4, MLN and spleen extracts, respectively, from mice inoculated with SSM 3213; 5 and 6, MLN and spleen extracts, respectively, from mice inoculated with SSM 3214; 7 and 8, MLN and spleen extracts, respectively, from mice inoculated with SSM 3215. Pooled MLN protein extracts from two mice were used in the experiments. Each lane was loaded with material from approximately $1 \times 10^{7}$ c.f.u. (b) Densitometric analysis of effector levels present in the whole bacterial extract. Effector levels were normalized to Cat expression and are presented in arbitrary units (a.u.). Data are means $\pm S D$ from three independent experiments. et al., 2005), additional functions of these effectors should not be ruled out.

The role of SopB in the inflammatory response and in fluid secretion in the infected ileum has been discussed earlier (Zhang et al., 2002). Furthermore, SopB could also participate in the development of murine salmonellosis after invasion and during the late stages of the disease. In this regard, it has been reported that SopB specifically stimulates inducible nitric oxide synthase (iNOS) production long after invasion (Drecktrah et al., 2005). Moreover, it has been suggested that SopB participates in the creation of a spacious phagosome in which Salmonella spp. resides (Patel \& Galan, 2005). Absence of $s o p D$ leads to a reduction of both fluid secretion and inflammatory responses during infection (Jones et al., 1998; Zhang et al., 2002). In vitro experiments using HeLa cells have shown that the expression of sopD is maintained at later stages of infection, suggesting that this effector may also play a role in systemic infection of the host (Brumell et al., 2003). Here, we demonstrate that SopD is still present in bacteria infecting MLNs and spleens during late stages of murine salmonellosis. These results are in complete agreement with those reported earlier that show that sopD mutants of serovar Typhimurium are significantly reduced in their ability to replicate in the mouse spleen (Jiang et al., 2004).

SopE2, a protein expressed by all strains of Salmonella, is introduced into host cells via the SPI-1 TTSS. Like its homologue SopE, SopE2 contributes to the bacterial invasion of epithelial cells (Buchwald et al., 2002; Wallis \& Galyov, 2000), and has also been implicated in the pathogenesis of diarrhoea and enteritis in calves (Zhang et al., 2002). It is not clear whether this effect of SopE2 is related to its role in bacterial invasion or to some other function. It is well documented that SopE2 regulates epithelial interleukin (IL)-8 production (Huang et al., 2004), and it is also involved in the upregulation of macrophage iNOS independently of effects on invasion (Cherayil et al., 2000). We detected SopE2 in serovar Typhimurium recovered from MLNs and spleens 8 days after ingestion. This is believed to be the first time that SopE2 has been associated to late stages of Salmonella infection. Interesting, although not yet fully understood, is the fact that SopE2 synthesis increases significantly in infected organs by day 5 post-i.p. inoculation. Further studies are required to shed light on the possible role of this effector protein during Salmonella systemic infection in mice.

In contrast to other $S$. enterica effector proteins, such as SopB, SopD and SopE2, relatively little is known about SopA. Earlier work has demonstrated a role for SopA in the Salmonella-induced movement of polymorphonuclear leukocytes across the intestinal epithelium (Wood et al., 2000) and shown that SopA acts in concert with other TTSS-1secreted effector proteins (Zhang et al., 2002). More recently, Layton et al. (2005) have reported that SopA localizes to mitochondria; the correlation of this fact with 
the role of SopA in virulence remains unknown. We detected SopA in serovar Typhimurium infecting MLNs and spleens, although in very small amounts.

AvrA protein from serovar Typhimurium inhibits activation of the key proinflammatory NF- $\kappa \mathrm{B}$ transcription factor and augments apoptosis in human epithelial cells (CollierHyams et al., 2002). Interestingly, the avrA gene is prevalent in the majority of $S$. enterica serovars; however, only a small number of them usually produce the protein (Streckel et al., 2004). Ben-Barak et al. (2006) have demonstrated that avrA expression is dependent on a specific regulatory function which appears to be differently modulated in the distinct Salmonella serovars. In our in vitro experiments, the lack of AvrA detection is remarkable, and might be due to nonpermissive expression conditions in our standard culture procedure. Indeed, Streckel et al. (2004) have shown that some of the non-producer strains begin to produce AvrA in low-pH culture. On the other hand, the failure in the detection of AvrA in vivo is in agreement with the report of Lawley et al. (2006), who show that the avrA gene product lacks of an obvious role during long-term systemic infection; AvrA must be regarded as an effector protein involved in the enteritis pathway.

In summary, we detected in vivo the presence of SipA, SopB, SopD and SopE2 in serovar Typhimurium colonizing the MLNs and spleen for several days after inoculation. Further studies are needed to identify SPI-1-dependent functions at late stages of murine salmonellosis and to elucidate the mechanisms that facilitate the successful parasitic lifestyle of serovar Typhimurium.

\section{ACKNOWLEDGEMENTS}

We are very grateful to Ms María Isabel Bernal for her excellent technical assistance and to Dr Jorge Galán, Yale University School of Medicine, for providing strains. We thank Dr Graciela Pucciarelli and Dr Domínguez-Bernal for expert assistance with the preparation of bacterial extracts from internal organs. This work was supported in part by CONICET grant PIP 5534/04 and ANPCyT grant PICT 13366.

\section{REFERENCES}

Bajaj, V., Lucas, R. L., Hwang, C. \& Lee, C. A. (1996). Co-ordinate regulation of Salmonella typhimurium invasion genes by environmental and regulatory factors is mediated by control of hilA expression. Mol Microbiol 22, 703-714.

Ben-Barak, Z., Streckel, W., Yaron, S., Cohen, S., Prager, R. \& Tschape, H. (2006). The expression of the virulence-associated effector protein gene avrA is dependent on a Salmonella entericaspecific regulatory function. Int J Med Microbiol 296, 25-38.

Brown, N. F., Vallance, B. A., Coombes, B. K., Valdez, Y., Coburn, B. A. \& Finlay, B. B. (2005). Salmonella pathogenicity island 2 is expressed prior to penetrating the intestine. PLoS Pathog 1, 252-258. Brumell, J. H., Kujat-Choy, S., Brown, N. F., Vallance, B. A., Knodler, L. A. \& Finlay, B. B. (2003). SopD2 is a novel type III secreted effector of Salmonella typhimurium that targets late endocytic compartments upon delivery into host cells. Traffic 4, 36-48.

Buchwald, G., Friebel, A., Galan, J. E., Hardt, W. D., Wittinghofer, A. \& Scheffzek, K. (2002). Structural basis for the reversible activation of a Rho protein by the bacterial toxin SopE. EMBO J 21, 3286-3295.

Cherayil, B. J., McCormick, B. A. \& Bosley, J. (2000). Salmonella enterica serovar Typhimurium-dependent regulation of iNOS expression in macrophages by invasins SipB, SipC, and SipD, and effector SopE2. Infect Immun 68, 5567-5574.

Clark, M. A., Jepson, M. A., Simmons, N. L. \& Hirst, B. H. (1994). Preferential interaction of Salmonella typhimurium with mouse Peyer's patch M cells. Res Microbiol 145, 543-552.

Coburn, B., Li, Y., Owen, D., Vallance, B. A. \& Finlay, B. B. (2005). Salmonella enterica serovar Typhimurium pathogenicity island 2 is necessary for complete virulence in a mouse model of infectious enterocolitis. Infect Immun 73, 3219-3227.

Collier-Hyams, L. S., Zeng, H., Sun, J., Tomlinson, A. D., Bao, Z. Q., Chen, H., Madara, J. L., Orth, K. \& Neish, A. S. (2002). Cutting edge: Salmonella AvrA effector inhibits the key proinflammatory, antiapoptotic NF-kappa B pathway. J Immunol 169, 2846-2850.

Dominguez-Bernal, G., Pucciarelli, M. G., Ramos-Morales, F., Garcia-Quintanilla, M., Cano, D. A., Casadesus, J. \& Garcia-del Portillo, F. (2004). Repression of the RcsC-YojN-RcsB phosphorelay by the IgaA protein is a requisite for Salmonella virulence. Mol Microbiol 53, 1437-1449.

Drecktrah, D., Knodler, L. A., Galbraith, K. \& Steele-Mortimer, O. (2005). The Salmonella SPI1 effector SopB stimulates nitric oxide production long after invasion. Cell Microbiol 7, 105-113.

Galan, J. E. (2001). Salmonella interactions with host cells: type III secretion at work. Annu Rev Cell Dev Biol 17, 53-86.

Galan, J. E. \& Curtiss, R., III (1989). Cloning and molecular characterization of genes whose products allowed Salmonella typhimurium to penetrate tissue culture cells. Proc Natl Acad Sci U S A 86, 6383-6387.

Huang, F.-C., Werne, A., Li, O., Galyov, E. E., Walker, W. A. \& Cherayil, B. J. (2004). Cooperative interactions between flagellin and SopE2 in the epithelial interleukin-8 response to Salmonella enterica. Infect Immun 72, 5052-5062.

Jiang, X., Rossanese, O. W., Brown, N. F., Kujat-Choy, S., Galan, J. E., Finlay, B. B. \& Brumell, J. H. (2004). The related effector proteins SopD and SopD2 from Salmonella enterica serovar Typhimurium contribute to virulence during systemic infection of mice. Mol Microbiol 54, 1186-1198.

Jones, B. D., Ghori, N. \& Falkow, S. (1994). Salmonella typhimurium initiates murine infection by penetrating and destroying the specialized epithelial M cells of the Peyer's patches. J Exp Med 180, 15-23.

Jones, M. A., Wood, M. W., Mullan, P. B., Watson, P. R., Wallis, T. S. \& Galyov, E. E. (1998). Secreted effector proteins of Salmonella dublin act in concert to induce enteritis. Infect Immun 66, 5799-5804.

Kubori, T. \& Galan, J. E. (2003). Temporal regulation of salmonella virulence effector function by proteasome-dependent protein degradation. Cell 115, 333-342.

Lawley, T. D., Chan, K., Thompson, L. J., Kim, C. C., Govoni, G. R. \& Monack, D. M. (2006). Genome-wide screen for salmonella genes required for long-term systemic infection of the mouse. PLoS Pathog 2, e11.

Layton, A. N., Brown, P. J., Edouard, E. \& Galyov, E. E. (2005). The Salmonella translocated effector SopA is targeted to the mitochondria of infected cells. J Bacteriol 187, 3565-3571.

Lucas, R. L. \& Lee, C. A. (2000). Unravelling the mysteries of virulence gene regulation in Salmonella typhimurium. Mol Microbiol 36, 1024-1033. 
Marcus, S. L., Brumell, J. H., Pfeifer, C. G. \& Finlay, B. B. (2000). Salmonella pathogenicity islands: big virulence in small packages. Microbes Infect 2, 145-156.

Miki, T., Okada, N. \& Danbara, H. (2004). Two periplasmic disulfide oxidoreductases, DsbA and SrgA, target outer membrane protein SpiA, a component of the Salmonella pathogenicity island 2 type III secretion system. J Biol Chem 279, 34631-34642.

Mirold, S., Ehrbar, K., Weissmüller, A., Prager, R., Tschäpe, H., Rüssmann, H. \& Hardt, W.-D. (2001). Salmonella host cell invasion emerged by acquisition of a mosaic of separate genetic elements, including Salmonella pathogenicity island 1 (SPI1), SPI5, and sopE2. $J$ Bacteriol 183, 2348-2358.

Patel, J. C. \& Galan, J. E. (2005). Manipulation of the host actin cytoskeleton by Salmonella: all in the name of entry. Curr Opin Microbiol 8, 10-15.

Pfeifer, C. G., Marcus, S. L., Steele-Mortimer, O., Knodler, L. A. \& Finlay, B. B. (1999). Salmonella typhimurium virulence genes are induced upon bacterial invasion into phagocytic and nonphagocytic cells. Infect Immun 67, 5690-5698.

Pucciarelli, M. G., Prieto, A. I., Casadesús, J. \& Garcia-Del Portillo, F. (2002). Envelope instability in DNA adenine methylase mutants of Salmonella enterica. Microbiology 148, 1171-1182.

Raffatellu, M., Wilson, R. P., Chessa, D., Andrews-Polymenis, H., Tran, Q. T., Lawhon, S., Khare, S., Adams, L. G. \& Bäumler, A. J. (2005). SipA, SopA, SopB, SopD, and SopE2 contribute to Salmonella enterica serotype typhimurium invasion of epithelial cells. Infect Immun 73, 146-154.

Reed, L. J. \& Muench, H. (1938). A simple method of estimating fifty per cent endpoints. Am J Hyg 27, 493-499.

Reis, B. P., Zhang, S., Tsolis, R. M., Baümler, A. J., Adams, L. G. \& Santos, R. L. (2003). The attenuated $\operatorname{sop} B$ mutant of Salmonella enterica serovar Typhimurium has the same tissue distribution and host chemokine response as the wild type in bovine Peyer's patches. Vet Microbiol 97, 269-277.

Santos, R. L. \& Bäumler, A. J. (2004). Cell tropism of Salmonella enterica. Int J Med Microbiol 294, 225-233.

Schlumberger, M. C. \& Hardt, W. D. (2006). Salmonella type III secretion effectors: pulling the host cell's strings. Curr Opin Microbiol 9, 1-9.
Steele-Mortimer, O., Brumell, J. H., Knodler, L. A., Meresse, S., Lopez, A. \& Finlay, B. B. (2002). The invasion-associated type III secretion system of Salmonella enterica serovar Typhimurium is necessary for intracellular proliferation and vacuole biogenesis in epithelial cells. Cell Microbiol 4, 43-54.

Streckel, W., Wolff, A. C., Prager, R., Tietze, E. \& Tschäpe, H. (2004). Expression profiles of effector proteins SopB, SopD1, SopE1, and AvrA differ with systemic, enteric, and epidemic strains of Salmonella enterica. Mol Nutr Food Res 48, 496-503.

Tsolis, R. M., Kingsley, R. A., Townsend, S. M., Ficht, T. A., Adams, L. G. \& Baumler, A. J. (1999). Of mice, calves, and men. Comparison of the mouse typhoid model with other Salmonella infections. Adv Exp Med Biol 473, 261-274.

Uzzau, S., Figueroa-Bossi, N., Rubino, S. \& Bossi, L. (2001). Epitope tagging of chromosomal genes in Salmonella. Proc Natl Acad Sci U S A 26, 15264-15269.

Vazquez-Torres, A., Jones-Carson, J. \& Baümler, A. J. (1999). Extraintestinal dissemination of Salmonella via CD18-expressing phagocytes. Nature 401, 804-808.

Wallis, T. S. \& Galyov, E. E. (2000). Molecular basis of Salmonellainduced enteritis. Mol Microbiol 36, 997-1005.

Waterman, S. R. \& Holden, D. W. (2003). Functions and effectors of the Salmonella pathogenicity island 2 type III secretion system. Cell Microbiol 5, 501-511.

Wood, M. W., Jones, M. A., Watson, P. R., Siber, A. M., McCormick, B. A., Hedges, S., Rosqvist, R., Wallis, T. S. \& Galyov, E. E. (2000). The secreted effector protein of Salmonella dublin, SopA, is translocated into eukaryotic cells and influences the induction of enteritis. Cell Microbiol 2, 293-303.

Zhang, S., Santos, S. R. L., Tsolis, R. M., Stender, S., Hardt, W.-D., Baümler, A. J. \& Adams, L. G. (2002). The Salmonella enterica serotype Typhimurium effector proteins SipA, SopA, SopB, SopD, and SopE2 act in concert to induce diarrhea in calves. Infect Immun 70, 3843-3855.

Zhang, S., Adams, L. G., Nunes, J., Khare, S., Tsolis, R. M. \& Bäumler, A. J. (2003). Secreted effector proteins of Salmonella enterica serotype typhimurium elicit host-specific chemokine profiles in animal models of typhoid fever and enterocolitis. Infect Immun 71, 4795-4803.

Edited by: S. C. Andrews 